\title{
Access to Health Care Services by Individuals Who Are Deaf or Hard of Hearing (Dhh) in Botswana: Francistown and Tati
}

\section{Gorgeous Sarah Chinkonono}

Goteborgs Universitet

\section{Vivian Namuli}

Goteborgs Universitet

Catherine Atuhaire ( $\nabla$ catuhaire@must.ac.ug )

Mbarara University of Science and Technology Faculty of Medicine https://orcid.org/0000-0002-60287491

\section{Hamida Massaquoi}

Uppsala Universitet

\section{Sourav Mukhopadhyay}

University of Botswana

\section{Samuel Nambile Cumber}

University of the Free State

Research article

Keywords: Access, Botswana, Deaf, Hard of hearing, Healthcare services

Posted Date: June 15th, 2020

DOI: https://doi.org/10.21203/rs.3.rs-29186/v1

License: (c) (1) This work is licensed under a Creative Commons Attribution 4.0 International License. Read Full License 


\section{Abstract}

Background: Individuals who are Deaf or hard of hearing (DHH) face a lot of challenges when accessing health care services. The main barrier that they face is communication. Despite this, not much research had been carried out in Africa to understand how individuals who are $\mathrm{DHH}$ access healthcare services. This study sought to explore experiences of individuals who are $\mathrm{DHH}$ in Botswana when accessing healthcare services to propose recommendations towards improving their situation.

Methods: This is a qualitative research study using phenomenological approach. Participants were observed at one point in time. Face-to-face in-depth interviews were conducted with $22 \mathrm{DHH}$ individuals living in Francistown and Tati, using a semi-structured interview guide and an interpreter. Participants age range was between 18years to 40years. Purposive sampling and snowballing sampling techniques were used to select the participants.

Results: The main challenge that individuals who are DHH in Botswana face is communication barrier which has culminated in their reception of poor healthcare services as the healthcare professionals fail to effectively attain to their health needs. This is evident through wrong prescriptions and treatment; poor counselling services, lack of confidentiality; poor maternal health services especially during child delivery; and limited health information. However, individuals who are DHH in Botswana continues to utilise healthcare services.

Conclusion: Poor communication between healthcare professionals and individuals who are $\mathrm{DHH}$ act as an impediment to acquiring proper healthcare services by individuals who are $\mathrm{DHH}$. This can lead to poor health outcomes for the DHH population as they are not well informed about health issues that they are at risk of and at times do not know where to seek specific healthcare services pertaining to the health problems they are experiencing. Therefore, there is a need to provide sign language interpreters in the healthcare centres to reduce the impact of this problem.

\section{Background}

In comparison to the rest of the population, people with disabilities experience some form of disparities when accessing healthcare services [1], [2]. Access to healthcare is not just about the availability of healthcare services but rather, it is about the population using these services as per their needs, that is, healthcare services should be appropriate to the needs of the population [3], [4] as being able to access healthcare services without hindrances improves a population's health [5]. According to Donabedian [3] there are barriers to accessing healthcare services and these barriers "are not only financial but also psychological, informational, social, organisational, spatial, temporal and so on." Therefore, taking into consideration factors that hinder access to healthcare will help in addressing these issues in order to improve healthcare access. By defining access to healthcare, Gulliford et al [5] narrowed down this definition into four dimensions: service availability; utilisation and reduced barriers; relevance, effectiveness; and equity. 
Easy access to healthcare services plays an important role in attainment of good health and is a move towards achieving universal health coverage, hence the need to ensure that every individual can seek help from the healthcare facilities without any barriers [6]. The Deaf community is not well understood by the hearing population. Consequently, they are not provided with the best healthcare services when seeking help [7], [8]. Majority of individuals who are DHH are illiterate, have high unemployment rate, and experience difficulties in accessing services, healthcare services inclusive [7]. Most healthcare service providers have little or no knowledge about the Disability Act, leading to non-compliance to the act and without compliance to this Act, DHH population is not catered for [9]. Healthcare services are available for individuals who are DHH to access and use at any time both in high- and low-income countries, however, they do not cater for their special needs. According to Lawthers et al [10], healthcare systems have difficulties in providing proper healthcare services that meet the different needs of people with disabilities. Different studies had shown that there are barriers that hinders individuals who are DHH from accessing healthcare services. For instance, studies carried out in Australia, the UK, New Zealand and the US, about individuals who are DHH had revealed that indeed healthcare services are there for individuals who are $\mathrm{DHH}$ to access and there is a provision of a sign language interpreter, however, the interpreter is not always available to offer services to individuals who are DHH as they have to be booked first [11][14]. In Nepal, sign language interpreters are available but at times they are not because of lack of funding [15].

In Botswana, the preferred language for individuals who are $\mathrm{DHH}$ is sign language. However, sign language is not well known in Botswana as it is not considered as a "potent language" [16]. According to Lekoko and Mukhopadhyay [16], a situation whereby the health providers are unable to communicate in sign language may endanger the lives of individuals who are DHH seeking healthcare services. This is because individuals who are $\mathrm{DHH}$ too rely on health service providers for information regarding their health condition and well-being. For instance, it has been evident that individuals who are DHH in Botswana have less knowledge about HIV/AIDS because HIV/AIDS messages are not tailored in the way that they understand [17]. Further, a study carried out in Botswana about living conditions of people living with disabilities (PLWDs) had revealed that PLWDs inclusive of individuals who are DHH have poor health outcomes compared to those without disabilities [18]. It is the role of a healthcare in Botswana to educate the population about health [19], as good knowledge about health increases the health seeking behaviour among individuals who are $\mathrm{DHH}$ [20]. However, there is no research tracking, documenting and identifying the challenges that individuals who are $\mathrm{DHH}$ encounter when accessing healthcare services and how to address these challenges in Botswana. Therefore, the main aim of this study is to explore the experiences of individuals who are $\mathrm{DHH}$ in accessing healthcare services in Botswana to propose recommendations towards improving their situation.

\section{Methods}

\section{Study design}


This study applied qualitative approach, by adaptation of phenomenological perspective to understand the experiences of individuals who are $\mathrm{DHH}$ when accessing healthcare services.

\section{Study Setting}

The respondents were recruited using the school in Tati that admits DHH students and an organisation for people living with disabilities in Francistown called Lentswe la bana le bogole. The student respondents (2) and assistant teachers (2) were recruited through one of the schools that integrate learners who are $\mathrm{DHH}$. The school chosen is one of the two junior secondary schools in Botswana that have a Special unit for DHH students. It is located in Tati town and it admit individuals who are DHH and those who cannot speak but can hear. The school currently has 50 enrolled students in their Special units with an age range of 17 to 24 years. An organisation for people living with disabilities, Lentswe la ba na le bogole, assisted with recruiting the respondents who stay in Francistown. This organisation is based in Francistown and have an overall number of 89 registered people with disabilities and has about 25 individuals who are $\mathrm{DHH}$, who live in Francistown and surrounding areas.

\section{Population and sampling technique}

22 individuals who are DHH participated in this study between 13 March 2019 and 20 April 2019. The respondents were recruited through purposive sampling and snowballing. Individuals who are DHH who met the selection criteria were interviewed and after the interview the respondent would refer the researcher to the next participant.

\section{Inclusion and exclusion criteria}

The following criteria was used to include the respondents for this study within the population of interest

- Individuals who are DHH who use sign language taught in Botswana schools as a mode of communication.

- Individuals who are DHH and are aged 18 years and above

- Those who do not use taught sign language were excluded as it would be difficult to communicate with them.

- Everyone who is hard of hearing, uses sign language but can communicate at times using spoken language in combination with lip reading was excluded from the study.

The reasons for taking individuals who only uses sign language (the Deaf) is because, they share the same Deaf culture and it is assumed that they do not have the same communication challenges as those who can use spoken language in combination with lip reading (hard of hearing).

\section{Data Collection}

Face-to-face in-depth interviews were utilised to collect data from the participants. In this study, the first author gathered information from the respondents in a form of conversation with the help of a sign 
language interpreter. Through the conversation with the respondents, the researcher gained more insight about the experiences of individuals who are $\mathrm{DHH}$ when accessing healthcare services. The conversation between the interpreter and the researcher were audio recorded through a phone recorder for transcription purpose. The researcher scribbled some notes for probing purposes. The interviews lasted between 11 minutes to 45 minutes with an average mean of 21 minutes per interview.

The respondents recruited through school were held at school in an area that was selected by the respondents, and they all chose an outdoor sitting area. Respondents recruited through Lentswe la ba na le bogole were interviewed at their workplaces in a secluded area while three participants were interviewed in a less busy restaurant close to their workplace. During the interview, the researcher was asking questions in English and the interpreter was interpreting in both sign language for the respondents and in English for the researcher. A female sign language interpreter was used during all the interviews.

A semi-structured interview guide, that consisted of four questions was used during data collection. The interview guide was created based on the aim of the study and probing was guided by the respondent's response. Two respondents were used for piloting purpose to validate the interview tool, however, they were not excluded when doing analysis.

\section{Data Analysis Plan}

Thematic analysis was used to analyse the findings of this study. Themes and patterns were identified in the data to show experiences of the participants. Data analysed in this study is strictly from the transcripts and present the opinions and experiences of the respondents in relation to access to healthcare services.

The audio recordings from the interviews were transcribed into English. The transcripts were then coded manually using a table to pinpoint all the statements in the data that explain and describes how access to healthcare services is like for DHH population in Francistown and Tati. The codes were then grouped into different themes and sub-themes depending on their similarity which were then named. Presentation of themes and sub-themes was carried out with the use of some quotes that were extracted from the transcripts.

\section{Ethical Considerations}

The researcher obtained ethical clearance for conducting the study from relevant authorities in Botswana, Ministry of Health and Wellness for overall study and Ministry of Education and Skills Development for interviewing student respondents. Upon receiving ethical approval, the researcher obtained consent from the respondents before recording the conversation. Confidentiality was ensured and interviews were held in a place that allowed for privacy selected by the respondents.

\section{Results}




\section{Characteristics of Study Participants}

These results represent the experiences of the 22 individuals (12 females and 10 males) who are DHH in Botswana when accessing healthcare services. The age of the respondents interviewed ranged between 18 to 40 years and the mean age was 29 years. Majority of the respondents were teachers (13), 2 cleaners, 2 students, 2 gardeners, 2 hotel porters and I child caretaker. 10 respondents had attained Junior level of education, 4 senior level, 2 vocational and 4 tertiary level of education. 4 respondents were interviewed in Tati and 18 in Francistown.

Four themes were derived from the data collected and these are; Quality of healthcare services; Barriers to healthcare access; Utilisation of healthcare services; and Recommendations (Table 1).

Table 1

Themes derived from the data collected

Experiences of individuals who are DHH
1. Quality of healthcare services
- Treatments and medications
- Maternal services
2. Barriers to healthcare services
- Distance to see a specialist
- Communication barrier
- Privacy and confidentiality
- Lack of health information
3. Utilisation of healthcare services
4. Recommendations
- Provision of interpreters
- Provision of health promotion and education to individuals who are DHH
- Provision of HIV testing centres for individuals who are DHH

\section{Quality Of Healthcare Services}

In relation to medications and treatment offered in healthcare centres, majority of the participants raised a concern that they are not given the best healthcare services as many of them indicated that they are given medications without any explanation of how to use them. However, they appreciated the 
instructions that are on the medication containers as they have pictures and some writings on them hence, they can read and understand how to take the medications. Some of the participants stated that healthcare personnel perform some medical procedures on them without any explanation of why they are carrying out those procedures as per the below comment:

"I do not like injections and being put on drips because they do not tell me why they put those things on me, they just put them or inject me. I hate it when doctors just do things on me without telling me why." (Female, 27)

One of the respondent was worried that he does not trust the medical prescriptions that he is given as he felt that the communication between them and the healthcare workers is so poor that they just prescribe medications without a clear understanding of what they are suffering from as shown by the comment below:

"Sometimes they give me wrong medication because communication will be so small, so sometimes they don't understand at all. I will be trying to explain deep what I am suffering from and they will be understanding only few...the doctor does not write anything for me to read, most times it's only me writing while he reads." (Male, 37$)$

When explaining their pregnancy and birth giving experiences at the hospital, majority of female participants who had given birth had received poor sexual reproductive health services from the healthcare professionals. The only antenatal care that they are given at the healthcare centres is the checking of their health and that of the baby through tests and ultrasound scans. When it comes to how they are supposed to care for themselves and the baby during and after pregnancy, no information is shared with them. This was stipulated in the comment below:

"When giving birth the doctor will be showing me what I should do (sarcastically imitating breathing exercises told to do by doctors) and I will be just copying... They show me the needle and show that they are going to stitch me. They do not teach me how to care for the stitches... My mother taught me everything when I got home" (Female, 37)

However, one female participant stated that the use of pictures is helpful during child delivery as she was able see what is expected of her in the delivery room.

Individuals who are DHH have no access to counselling services in the healthcare centres in Botswana. Most of participants, except one participant did not know that there are Social workers and psychologists who offer counselling in the healthcare centres, rather they used doctors who offered lay counselling. None of the respondents who mentioned having acquired counselling from the doctors were referred to a professional counsellor. The following comment by a participant shows this dissatisfaction:

"I always tell the doctor when I am at the hospital that I have stress and the doctor will say, "sorry you will be okay" then I will go home......No, I have never been referred to a Social worker, I always talk with a 
doctor.....Yes, I will have went because I was stressed and the doctor did not help. He just said I will be okay." (Female, 27)

\section{Barriers To Healthcare Access}

All the participants had stated that healthcare facilities are available in the areas that they are in and are within reach as they are a walking distance. Even though that is the case, four participants who need to see an audiologist on yearly basis complained that the audiologist is in Gaborone (capital city, which is $435 \mathrm{kms}$ from Francistown). The following statement was made by the participant:

"...in Francistown, there is no audiologist, we always have to go to Gaborone for the audiologist... We are Deaf, we sometimes need to see an audiologist... it is very hard for us because we have to pay bus fare, and where are we going to sleep in Gaborone, so it is a problem. What are you going to eat? We are going to be poor." (Male, 37)

All the participants had stated that the doctors fail to communicate with them when they seek their services. Most of the doctors resort to assisting individuals who are $\mathrm{DHH}$ through written communication, which majority of the respondents in this study had stated that they did not fully understand. As much as the healthcare service providers are unable to communicate with DHH population, individuals who are DHH had observed that when they are assisted by the same doctor many times, the communication between them and that doctor improves. However, after establishing this level of understanding with the doctor, the doctor will be moved somewhere else and they must go through the same communication challenge again with the new doctor as highlighted in the following comment:

"There will be an old doctor who understand and communication is better but when the new person comes, communication becomes hard. If only one doctor helps us, it will be easy to communicate." (Male, 33)

Majority of the participants indicated that at times they are accompanied by a friend or family member when seeking healthcare services. Most of the participants except three participants have no problem with having a third party in the consultation room. However, in relation to HIV/AIDS testing, majority of the respondents do not want a third person in the testing room for confidentiality reasons hence, they had shown disappointment concerning the closure of the HIV/AIDS testing centres that were specifically meant for individuals who are $\mathrm{DHH}$. As shared in the sentiment below:

"Before, HIV testing centres for the Deaf were there, we were happy because we had testing services in Francistown. We celebrated its opening and now that it is closed, we do not know why?... In some of the things that are secretive like HIV/AIDS testing, I want only the person who is testing me not a third person, so if there is a need to call someone to help with communication, I will not go and test." (Male, 37)

Majority of the participants complained about not being educated about health issues at the hospital or clinics as it is the case with the hearing population. For instance, of all the participants interviewed, only 
five respondents ( 1 male and 4 females) knew about other methods of pregnancy prevention while the rest only knew about the use of a condom. However, the respondents accredited schools and Botswana Association of the Deaf (BOAD) for health information.

"We do not know about sexual things while the language people know. The doctors have never taught me about pregnancy. The people who can hear get information about pregnancy prevention because they speak the same language as the doctors but with us the Deaf, we use sign language and the doctors do not know sign language, so I was never taught about pregnancy prevention methods. I only knew after I had my child." (Female, 37)

When explaining about the type of health education they receive from BOAD and schools, HIV/AIDS, cancer and healthy living (healthy eating and exercising) were the only examples that the participants mentioned. It was stated that BOAD host educational workshops for individuals who are DHH once a year.

Despite all these challenges, majority of the participants except three stated that they utilise healthcare services as it is better to seek help than being home while one is sick. The following sentiment was shared by one of the participants:

"When I am sick, I go to the hospital because I have no choice. What if I do not go because of no communication and stay home and die? Its better I go to the hospital and try using signs. I respect the doctors and I am open to them about my sickness." (Male, 37)

\section{Utilisation Of Health Care Services}

Despite the poor services and the barriers that individuals who are DHH are faced with when accessing healthcare services, individuals who are DHH always visit the hospital to seek health services when they are sick. Individuals who are $\mathrm{DHH}$ had shown some resilience and determination towards living healthy lives and get help no matter how little it is from the healthcare services.

When I am sick, I go to the hospital because I have no choice. What if I do not go because of no communication and stay home and die? Its better I go to the hospital and try using signs. I respect the doctors and I am open to them about my sickness - Male, 37

Only three participants mentioned that they are at times demotivated to seek healthcare services because of lack of communication and privacy.

\section{Recommendations}

Many participants suggested that they be provided with interpreters in the hospitals however, some participants felt that it is best if healthcare providers can communicate using sign language as this will make things easy for them. One of the participants mention that: 
"If we have an interpreter, they may spread our secrets. Therefore, the doctors should learn sign language so that we communicate directly with them as they do with those who speak." (Male, 26)

In relation to health education, majority of the participants had shown interest in being taught about health issues. They want to be well informed about sexual reproductive health and what is expected of them during pregnancy. One of the participants suggested visualised method of education about pregnancy and giving birth as this will be easier for them to understand what happens when one gives birth. Seven out of 12 female respondents had children.

"There are no teachings about giving birth and what to do when pregnant for the Deaf. If there were videos that show what happens when one is pregnant and what they are supposed to do when giving birth and after giving birth, it will be better as we will be able to learn." (Female, 37)

Majority of the participants recommended the re-opening of HIV/AIDS testing centres that have sign language interpreters. They indicated that they benefited a lot from the HIV/AIDS testing centre that was opened specifically for them as they were able to communicate with the service providers without any barrier and they were offered HIV/AIDS information.

"We used to have an HIV testing centre for the Deaf and it has been closed. The government should open it again." (Female, 23)

\section{Discussions}

The findings of this study had shown that although the healthcare centres are available and within reach for the individuals who are $\mathrm{DHH}$, the services that they receive are not of good quality due to the language barrier that exist between them and the healthcare service providers. The ingredient to making a good diagnosis is done through a good conversation between the patient and the doctor [9], however, individuals who are $\mathrm{DHH}$ miss out on that. A study that was carried out in the US on misinterpretation of psychiatric illness had revealed that indeed individuals who are $\mathrm{DHH}$ are wrongly diagnosed at times leading to wrong treatment [21]. Adherence to medication is one of the factors that brings about good health outcomes. For one to adhere to medication, they have to receive appropriate guidance from the pharmacist and individuals who are DHH miss out on this leading to poor health outcomes [22]. According to Botswana National Drug (Medicine) Policy (BNDP), the community should be imparted with knowledge about the use of medications that they are given at the healthcare centres [23] which is contrary to the findings of this study as it had revealed that, individuals who are $\mathrm{DHH}$ are not given any information concerning the medications that they receive at the health facilities. This finding is backed by the results of the study carried out in the US on experiences of individuals who are DHH on healthcare access, where individuals who are $\mathrm{DHH}$ mentioned that, they receive treatments and medications that they are not knowledgeable about [24].

Individuals who are DHH struggle with understanding written English, which most healthcare providers assume they are conversant with and resort to assisting them through written communication [12], [25]- 
[27]. The same finding was discovered in this study, as majority of the respondents stated that they only understood few things when communicating with doctors through written communication. Therefore, for better healthcare access, writing should be used together with sign language [28]. However, according to the findings of a study carried out in South Africa by Kritzinger [29], communication between a doctor and an individual who is $\mathrm{DHH}$ tends to improve if an individual who is $\mathrm{DHH}$ is always assisted by the same healthcare provider as they form a relationship during all the visits to the healthcare. The same finding was also revealed in this study as the respondents indicated that they prefer to be serviced by the same doctor.

Individuals who are $\mathrm{DHH}$ do not feel free to seek healthcare services on issues that they view as personal or confidential in the presence of a third party [29], [30]. This study discovered the same results as individuals who are DHH insisted that they will not go for HIV/AIDS testing in the presence of another person. Confidentiality and respect for one's privacy are some of the ethics that need to be observed by the healthcare service providers when offering HIV/AIDS counselling and testing [31]. However, it is evident that individuals who are $\mathrm{DHH}$ have no choice but to use family members to accompany them when seeking healthcare services because of communication barrier with the healthcare service providers [27], [29], [30].

According to Karlström et al, a healthy pregnancy and delivery depend on the tools a midwife equips an expectant woman with [32]. Despite how critical the role of the midwife is during labour, this study found out that, there is no assistance offered to $\mathrm{DHH}$ women during delivery as none of the healthcare professionals attending to them can use sign language and there is no interpreter available during this critical moment. A study carried out in South Africa, on pregnancy and maternity among individuals who are $\mathrm{DHH}$ had discovered that miscarriage cases were high among this population (31\%) in comparison to the population based study (16\%) [33]. Even though the study by Gichane et al [33], did not associate the miscarriages with poor maternal health services, one can argue that since all individuals who are $\mathrm{DHH}$ in the study enrolled for antenatal care, the services might not have been of good quality due to communication barrier, hence miscarriages occurred. According to, General Comment 22, Article 12, of the International Covenant on Economic, Social and Cultural Rights, all individuals in consideration of their special needs like disability should be provided with adequate sexual reproductive health information [34]. Yet, this study findings discovered that, individuals who are DHH are lacking in terms of health information especial sexual reproductive health as despite having given birth, most of female respondents did not know any methods of pregnancy prevention except condoms.

Individuals who are $\mathrm{DHH}$ are likely to experience mental health issues, as half of individuals who are $\mathrm{DHH}$ have high probability of suffering from mental health problem [35]. Despite this finding, individuals who are DHH do not have easy access to proper mental health services or counselling services. It was evident in this study that individuals who are $\mathrm{DHH}$ have no access to counselling services when they are under a lot of distress. The study by Anderson et al [20], had discovered that individuals who are DHH do not seek professional counselling because they are unaware of where to get these services which is in line with the findings of this study. A continued stress affects one's mental wellbeing leading to mental health 
problems [36], hence one can argue that this is the cause of high mental health cases among DHH population.

The study in Ghana had discovered that healthcare services by specialists are usually far and expensive to access, making it difficult for individuals who are $\mathrm{DHH}$ to utilise them [37]. This discovery is verified by the findings of this study that the audiologist services are located $435 \mathrm{~km}$ away from where respondents in this study stay. Accessing these services becomes costly on their side as they must travel for hours to use them. Various literature has stated that, to better service people, their needs have to be put into consideration [38], [39], hence this shows that the healthcare is lacking in meeting the needs of individuals who are $\mathrm{DHH}$.

Botswana offers free healthcare services to its citizens. People living with disabilities are given priority when accessing these services as they are excluded from queuing [19]. Despite the challenges that they face in accessing healthcare services, this study result had shown determination in seeking health services among individuals who are $\mathrm{DHH}$. Contrary to the above finding, a study carried in Brazil had found out that individual who are $\mathrm{DHH}$ shun away from using healthcare services because of the barriers that they come across [40].

Individuals who are $\mathrm{DHH}$ wish that healthcare services can be improved to meet their needs. Unlike other countries that offer interpreters for individuals who are DHH (South Africa, US, UK, Australia) [11]-[14], [29], Botswana has no interpreters available to assist individuals who are $\mathrm{DHH}$. There is a society for individuals who are DHH in Botswana, Botswana Society for the Deaf (BSD), which their mandate is to promote the rights and welfare of individuals who are $\mathrm{DHH}$ in the country. However, in their website, interpretation services are not listed among the services that they offer [41]. Even though the above mentioned countries (e.g., South Africa) offer interpretation services, they are not offered for free and the interpreters are not always available to assist when required [29]. Therefore, this calls for the need to provide free and accessible interpretation services to individuals who are $\mathrm{DDH}$. It was evident in a study by Anderson et al, that individuals who are $\mathrm{DHH}$ prefer to seek services from service providers that know sign language than the ones that do not [20]. The same finding was discovered in this study. However, the education curriculum of the healthcare providers does not include training them on how to assist individuals who are $\mathrm{DHH}$ or people with disabilities [40]. Lack of understanding of individuals who are $\mathrm{DHH}$ and their culture had been found to be the one that increases inequities that individuals who are DHH are faced with in healthcare centres [29].

Knowledge about health increases one's health seeking behaviour as this was evident on the findings of the study by Anderson et al [20], about individuals who are DHH and trauma counselling. Individuals who are $\mathrm{DHH}$ have shown so much interest in being educated about health issues, as they desire to be well informed as the hearing population [29], [37], [42]. The sense that functions at its best among individuals who are $\mathrm{DHH}$ is visual sense, as they are visual people and learn best when things are shown in a visual format [43]. Therefore, the use of television for health education has been suggested by individuals who 
are $\mathrm{DHH}$ [29]. For this reason, the healthcare should provide health education to individuals who are $\mathrm{DHH}$ in a way that they will understand.

It is important that everyone in Botswana has an easy access to HIV/AIDS related health services as Botswana has a high HIV prevalence of $16.5 \%$, with an estimated number of 380,000 individuals who are HIV positive from the population of 2.3 million [44]. Therefore, these services should be offered in a way that they are acceptable by the individuals who are $\mathrm{DHH}$, hence there is a need to open an HIV testing centres that caters for this population.

\section{Limitations}

Even though the findings of this study can be applicable to the general population of individuals who are $\mathrm{DHH}$, the findings are subjective rather than objective, that is, they are based on personal feelings and individual experiences. Children were not included in this study. Most of the respondents worked as assistant teachers, 13 out of 20 respondents and they had only completed basic education except for two assistant teachers who went to tertiary.

\section{Conclusion}

Failure to communicate in sign language by the healthcare professionals has disadvantaged individuals who are $\mathrm{DHH}$ in Botswana when it comes to accessing healthcare services. This had led to individuals who are $\mathrm{DHH}$ receiving poor healthcare services and not being knowledgeable about health issues, hence limiting their health choices like, pregnancy prevention methods. Further, it can be risky for female individuals who are $\mathrm{DHH}$ to give birth without the assistance of the midwife as it can lead to delivery complications. Therefore, there is a need to provide interpretation services for individuals who are $\mathrm{DHH}$ at least in critical situation like during delivery of the baby and surgery. Also, healthcare professionals should learn basic sign language to eliminate communication barrier that exist between them and individuals who are $\mathrm{DHH}$.

\section{Recommendations}

Individuals who are $\mathrm{DHH}$ should be informed about the variety of services that they can receive from the healthcare centres rather than just viewing them as a place that one gets medical assistance only. The more knowledgeable they are about these services, the high the chances that they will know where to go when in need of help like counselling. The results of this study revealed that individuals who are DHH do not know where to go for counselling rather they seek counselling services from the doctors. This shows lack of knowledge about services that are offered in the healthcare centres.

As of current, sign language is not viewed as an important language in Botswana [16]. If sign language is recognised as a language, whenever there is a move towards introducing other indigenous languages in Botswana schools, sign language will be among those languages. Recognition of sign language as one 
of the languages that exist in Botswana can be one of the steps toward eliminating the communication barrier that exist between the hearing population and individuals who are $\mathrm{DHH}$.

\section{Abbreviations}

\section{BNDP}

Botswana National Drug (Medicine) Policy; BOAD:Botswana Association of the Deaf; BSD:Botswana Society for the Deaf; DHH:Deaf or Hard of Hearing; PLWDs:People Living with Disabilities; USA:United States of America; UK:United Kingdom

\section{Declarations}

\section{Ethical approval and consent to participate}

Ethical approval was obtained from the Ministry of Health and Wellness and Ministry of Education and Skills Development - Basic Education (North East Region) in Botswana.

The participants were requested to provide written consent and the voices of an interpreter and interviewer were recorded using an audio recorder. Consent was obtained first from the respondents before recording.

\section{Consent for publication}

Not applicable

\section{Availability of data and material}

Interview scripts can be shared by the first author, Gorgeous Sarah Chinkonono upon requestbut restrictions apply under license for the current study. The data may be made publicly available upon reasonable request and with permission of Ministry of Health and Wellness and Ministry of Education and Skills Development - Basic Education (North East Region) in Botswana.

\section{Competing interests}

The authors declare that they have no competing interests.

\section{Funding}

No funding for this study

\section{Authors' contributions}

GSC,SM and SNC conceived and conducted the study. GSC and VN implemented the study and conducted data analysis.SNC and SM offered technical guidance throughout the study. GSC and CA 
wrote the first draft of the manuscript. GSC, CA, VN, SM, HM and SNC reviewed and corrected the draft manuscript. All authors read and approved the final manuscript.

\section{Acknowledgement}

Our gratitude goes to the participants of this study for sharing their experiences and their valuable time.

\section{References}

1. World Health Organization (WHO). "World Report on Disability," 2011.

2. Tomlinson M, Swartz L, Officer A, Chan KY, Rudan I, Saxena S. Research priorities for health of people with disabilities: an expert opinion exercise. Lancet. 2009;374(9704):1857-62.

3. Donabedian A, "Models for Organizing the Delivery of Personal Health Services and Criteria for Evaluating Them Author (s): Avedis Donabedian Source: The Milbank Memorial Fund Quarterly, Vol. 50, No. 4, Part 2 : Medical Cure and Medical Care : Prospects for the 0," Milbank Mem. Fund Q., vol. 50, no. 4, pp. 103-154, 1972.

4. Halfon N. Non-Financial Barriers to Care for Children and Youth. Annu Rev Public Health. 1995;16(1):447-72.

5. Gulliford M, et al. What does ' access to health care ' mean ? PubMed Commons. J Heal Serv Res Policy. 2002;7(3):186-8.

6. UN Economic and Social Council. "CESCR General Comment No. 14: The Right to the Highest Attainable Standard of Health (Art. 12 of the Covenant)," 2000.

7. Richardson KJ. "Deaf culture: Competencies and best practices," Nurse Pract., vol. 39, no. 5, 2014.

8. Eckert RC. Toward a theory of deaf ethnos: Deafnicity $\approx$ D/deaf: (Hómaemon • Homóglosson • Homóthreskon). J Deaf Stud Deaf Educ. 2010;15(4):317-33.

9. Harmer L. Health care delivery and deaf people: practice, problems, and recommendations for change, vol. 4, no. 2. 2002.

10. Lawthers AG, Pransky GS, Peterson LE, Himmelstein JH. "Rethinking quality in the context of persons with disability," International Journal for Quality in Health Care. 2003.

11. Earis H, Reynolds S. "Deaf and hard-of-hearing people's access to primary health care services in North East Essex A report for North East Essex Primary Care Trust," pp. 1-64, 2009.

12. Witko J, Boyles P, Smiler K, McKee R. Deaf New Zealand sign language users' access to healthcare. $N$ Z Med J. 2017;130(1466):53-61.

13. Terry DR, Lê Q, Nguyen HB. "Moving forward with dignity: Exploring health awareness in an isolated Deaf community of Australia," Disabil. Health J., 2016.

14. Cabral L, Muhr K, Savageau J. Perspectives of people who are deaf and hard of hearing on mental health, recovery, and peer support. Community Ment Health J. 2013;49(6):649-57. 
15. Devkota HR, Murray E, Kett M, Groce N. "Are maternal healthcare services accessible to vulnerable group? A study among women with disabilities in rural Nepal," 2018.

16. Lekoko RN, Mukhopadhyay S. "Practice and preferences of sign Languages in the Instruction of Deaf Students: Some Reflections on the Mainstream Secondary Schools of Botswana," vol. 19, no. 1, pp. 79-92, 2008.

17. Mukhopadhyay S, Moswela E, Molosiwa S. HIV / AIDS and Disability: Perspectives of Adolescents with Hearing Impairment on HIV and AIDS Prevention. Pula Botswana J African Stud. 2011;25(1):92-106.

18. Eide AH, Mmatli T. "Living conditions among people with disability in Botswana," SINTEF Rapp., 2016.

19. Republic of Botswana. "National Health Policy Towards a Healthier Botswana," no. August, 2011.

20. Anderson ML, Craig KSW, Ziedonis DM. Deaf people's help-seeking following trauma: Experiences with and recommendations for the Massachusetts behavioral health care system. " Psychol Trauma Theory Res Pract Policy. 2017;9(2):239-48.

21. Anglemyer E, Crespi C, "Misinterpretation of Psychiatric Illness in Deaf Patients: Two Case Reports," Case Rep. Psychiatry, vol. 2018, pp. 1-4, 2018.

22. Hyoguchi N, Kobayashi D, Kubota T, Shimazoe T. Effects on deaf patients of medication education by pharmacists. J Deaf Stud Deaf Educ. 2016;21(4):416-21.

23. Ministry of Health - Botswana. "Botswana National Drugs (Medicine) Policy," no. 1, 2005.

24. Steinberg AG, Wiggins EA, Barmada $\mathrm{CH}$, Sullivan VJOY. "Deaf Women: Experiences and Perceptions of Healthcare System Access," vol. 11, no. 8, 2002.

25. Warburton D. Ubido J, Huntington J. Inequalities in access to healthcare faced women who are deaf. Health Soc Care Community. 2002;Vol. 10(4):247-53.

26. McEwen E, Anton-Culver H. "The medical communication of deaf patients.," J. Fam. Pract., 1988.

27. DiPietro LJ, Knight CH, Sams JS. Health Care Delivery for Deaf Patients: The Provider's Role. Am Ann Deaf. 2013;126(2):106-12.

28. Wright GW, Reese RJ. Strengthening cultural sensitivity in mental health counseling for deaf clients. J Multicult Couns Devel. 2015;43(4):275-87.

29. Kritzinger J. "Exploring the barriers and facilitators to health care services and health care information for deaf people in Worcester," no. December, 2011.

30. Mprah WK. Perceptions about Barriers to Sexual and Reproductive Health Information and Services among Deaf People in Ghana. Disabil CBR Incl Dev. 2013;24(3):21.

31. Centers for Disease Control and Prevention. "Revised guidelines for HIV counseling, testing, and referral.," MMWR. Recomm. reports Morb. Mortal. Wkly. report. Recomm. reports, vol. 50, no. RR-19, pp. 1-57; quiz CE1-19a1-CE6-19a1, Nov. 2001.

32. Karlström A, Nystedt A, Hildingsson I. The effectiveness of financial incentives for smoking cessation during pregnancy: is it from being paid or from the extra aid? BMC Pregnancy Childbirth. 2012;12:24. 
33. Gichane MW, Heap M, Fontes M, London L, "'They must understand we are people': Pregnancy and maternity service use among signing Deaf women in Cape Town," Disabil. Health J., vol. 10, no. 3, pp. 434-439, Jul. 2017.

34. UN Economic and Social Council. "Committee on Economic, Social and Cultural Rights, General Comment No. 22, The Right to Sexual and Reproductive Health, UN Doc. No. E/C.12/GC/22," 2016.

35. Fellinger J, Holzinger D, Fellinger J, Holzinger D, Pollard R. “Mental health of deaf people," 2012.

36. Pearlin LI, Stress and mental health: A conceptual overview. - PsycNET. New York, 1999.

37. Senayah EA. "Barriers to Healthcare: The case of Students at Ashanti School for the Deaf, Jamasi.," Jan. 2017.

38. Exworthy T, Wilson S, Forrester A. Beyond equivalence: prisoners' right to health. Psychiatrist. 2011;35(06):201-2.

39. Atewologun D. "Intersectionality Theory and Practice PRINTED FROM the OXFORD RESEARCH ENCYCLOPEDIA, BUSINESS AND MANAGEMENT (oxfordre.com/business). (Intersectionality Theory and Practice.\&\#8221.

40. Chaveiro N, Porto CC, Barbosa MA. The Relation Between Deaf Patients and the Doctor. Braz J Otorhinolaryngol. 2009;75(1):147-50.

41. Botswana Society for the Deaf. "BSD | Services," 2019. [Online]. Available: http://www.botswanasocietyforthedeaf.org/services. [Accessed: 30-Apr-2019].

42. Rugoho T, Maphosa F. Challenges faced by women with disabilities in accessing sexual and reproductive health in Zimbabwe: The case of Chitungwiza town. African J Disabil. 2017;6(0):1-8.

43. Luckner J, Bowen S, Carter K. Visual Teaciiing Siralegies for Students Who Are Deaf or Hard of Heari ng. Teach Except Child. 2001;33(3):38-44.

44. Organisation WH, Country Profiles "HIV," 2019. [Online]. Available: http://cfs.hivci.org/countryfactsheet.html. [Accessed: 12-Jun-2019].

\section{Supplementary Files}

This is a list of supplementary files associated with this preprint. Click to download.

- COREQHealthcareserviceaccessinBotswana.docx

- PRCHD2000770R0.pdf 